\title{
Selected NDT Techniques in Heat Treatment Control
}

\author{
Petr Beneš ${ }^{1}$, Vilém Vítovec ${ }^{2}$ \\ ${ }^{1}$ Faculty of Mechanical Engineering, University of West Bohemia. Univerzitní 22, 30614 Plzeň. Czech Republic. \\ E-mail: pbenes@kmm.zcu.cz \\ 2MKV ozubená kola. Lochotínská 47, 30100 Plzeň. Czech Republic. E-mail: vilemvitovec@gmail.com
}

The article deals with the control possibilities of chemical heat treatment of two types the most frequently used steels using common non-destructive testing techniques of materials. Nitriding and cementation processes were chosen as chemical heat treatment. The properties and thus the quality of the layers formed by this chemical heat treatment were determined using the eddy current method, ultrasonic technique and also the acoustic emission technique. These selected techniques are frequently used to flaws detection, which also arise in chemical heat treatment processes. As the thickness and properties of the surface layers significantly affect the electrical and acoustic properties of the substrate material, these techniques can also be used to control the performance of chemical heat treatment without the need to engage in destructive metallographic techniques.

From the analyzes, the possibility of verifying the quality of chemical heat treatment using NDT techniques was confirmed. This could in the future lead to the possibility of including some NDT techniques in the process of material output control, both in the case of piece and serial production.

Keywords: NDT testing, case-hardening, acoustic emission, ultrasonic testing, eddy current testing

\section{Introduction}

Due to the fact that the verification of chemical heat treatment is a very important matter, many methods have been developed for its evaluation. These methods include, in particular, conventional methods which are destructive nature. Conventional methods include metallographic tests and also tests for evaluating the mechanical properties of the material, such as the impact testing or the tensile test. Very often the quality of chemical heat treatment or heat treatment is also evaluated by measuring hardness, which is enshrined in many standards.

Destructive verification methods irreversibly disrupt the integrity of the part, so in the case of piece production of for example gears, this is a method that cannot be used and verification of the surface condition of the part is limited to measuring only the surface hardness. This is, of course, a completely unsatisfactory way of verifying the quality of chemical treatment testing.

It is therefore quite evident that verification using non-destructive methods is more than desirable for practical reasons. From an economic point of view, the transition from destructive to non-destructive methods is also advantageous, It is important to realize that many companies already have equipment for NDT material testing, where this equipment is used for conventional purposes, ie to search for and quantify material flaw detection. One of the typical NDT methods, which are already used to a limited extent to evaluate the correctness of chemical heat treatment implementation is especially the eddy current method. $[1,2,3]$

The main goal of this paper is to show the possibilities of some basic NDT techniques, which are commonly available for use in evaluating the quality of chemical heat treatment or heat treatment implementation. Methods of ultrasonic testing, eddy currents and acoustic emission were selected among the used techniques. The aim was that the equipment could be used without the need to purchase new probes or other equipment, ie that the existing equipment used for conventional material flaws detection be used as much as possible.

The most common heat treatment mistakes include the following phenomena: $[4,5]$

- excessive residual stresses in the material

- excessive deformation

- insufficient depth of layer formed during chemical heat treatment

- change in grain size of the material

- structural and chemical heterogeneity

- non-compliance with the technological procedure at chemical heat tretament (wrong diffusion time, insufficient or poor quality protective atmosphere, incorrectly selected heating temperature and cooling rate, uniformity of cooling, etc.) 
- deterioration of surface quality

- internal oxidation

- presence of remaining austenite

There is currently no NDT inspection techniques of chemical heat treatment almost never used, or only to a small extent. This fact can be proved by a small number of science articles that would deal with this possibility.

The driving force behind the idea of quality control design of chemical heat treatment was a spur of MKV Gears s.r.o., as a manufacturer of gears has a vital interest in controlling the supplied gear, so as to reduce the cost of producing their orders resulting from errors incurred during chemical heat treatment. The requirements of the company work was focused on the evaluation of the suitability of traditional NDT methods for control applications chemical heat treatment. The obtained results were compared with destructive classical methods for evaluation.

The main and basic theoretical prerequisite for checking the correctness of chemical heat treatment using NDT is the hypothesis that chemical heat treatment will significantly affect the plastic, elastic and electrical properties of the material and thus affect the transmission of ultrasonic waves (or general acoustic waves) through the material or surface responses of nitride or case-hardening layers to eddy current.

\section{Experiment}

The experiment was performed on two types of steels: steel for carburizing process ČSN 14220
$(16 \mathrm{MnCr} 5)$ and steel for nitriding process ČSN 15330 (31CrMoV9). These materials are commonly used in practice for gears and large machinery. Cylindrical samples with a diameter of $40 \mathrm{~mm}$ and a height of about $20 \mathrm{~mm}$ were used as experimental samples.

Carburizing process was performed on samples made of $16 \mathrm{MnCr} 5$ steel. The carburizing was performed in powder with different carburizing times. The case-hardening time was chosen for each sample at 3, 6,12 hours. Different case-hardening times resulted in different depths of carburizing layer. Furthermore, the sensitivity of individual detection methods to inappropriately hardening process was verified for these carburizing samples. This techological mistake is usually caused by a change in the cooling rate during hardening process. Different cooling rates were achieved by insulating the samples into heat treatment foil, which is usually used as a passive protection of the material from the adverse effects of the surrounding atmosphere during hardening processes. The use of foil reduced the cooling rate of the samples.

Samples of $31 \mathrm{CrMoV} 9$ nitriding steel were used to verify the thicknesses of the nitride layers. The nitriding was performed in the gas atmosphere at $500^{\circ}$ $\mathrm{C}$ for 35 hours. This created a nitrided layer with a total thickness of $0.3 \mathrm{~mm}$. Subsequently, the upper nitride layer with values of $10,25,50$ and $70 \mu \mathrm{m}$ was removal by grinding for individual samples. This type of sample therefore represents nitrided samples with different thicknesses of the nitride layer. The abovementioned samples therefore represent a set of heat treatment or chemical heat treatment materials that simulate the most common mistakes in processes, which occur most often in practice.

Tab. 1 Steel $16 \mathrm{MnCr}$, measured hardness values HV1 for the carburizing process.

\begin{tabular}{|c|c|c|c|c|c|c|c|c|c|}
\hline Depth from surface $[\mathrm{mm}]$ & 0.05 & 0.10 & 0.15 & 0.20 & 0.25 & 0.30 & 0.35 & 0.40 & 0.45 \\
\hline carb. 3 hrs. & 285 & 283 & 279 & 251 & 235 & 220 & 190 & 186 & 173 \\
\hline carb. 6 hrs. & 295 & 293 & 283 & 278 & 255 & 242 & 210 & 204 & 195 \\
\hline carb. 12 hrs. & 298 & 306 & 320 & 327 & 327 & 324 & 310 & 307 & 292 \\
\hline
\end{tabular}

Tab. 2 Steel 16MnCr5, measured hardness values HV1 after the quenching process.

\begin{tabular}{|c|c|c|c|c|c|c|c|c|c|}
\hline Depth from surface $[\mathrm{mm}]$ & 0.05 & 0.10 & 0.15 & 0.20 & 0.25 & 0.30 & 0.35 & 0.40 & 0.45 \\
\hline Quench.without foil & 394 & 368 & 369 & 394 & 373 & 357 & 409 & 350 & 371 \\
\hline Quench.in foil & 244 & 203 & 180 & 214 & 176 & 244 & 183 & 212 & 239 \\
\hline
\end{tabular}

Tab. 3 Steel 31CrMoV9, measured hardness values HV1 after the nitriding process.

\begin{tabular}{|c|c|c|c|c|c|c|c|c|c|}
\hline Depth from surface $[\mathrm{mm}]$ & 0.05 & 0.10 & 0.15 & 0.20 & 0.25 & 0.30 & 0.35 & 0.40 & 0.45 \\
\hline Nitr. - removal $10 \mu \mathrm{m}$ & 1564 & 1370 & 1176 & 1577 & 1176 & 437 & 420 & 415 & 414 \\
\hline Nitr. - removal $25 \mu \mathrm{m}$ & 1041 & 988 & 1008 & 1130 & 823 & 742 & 488 & 438 & 436 \\
\hline Nitr. - removal $50 \mu \mathrm{m}$ & 1530 & 1501 & 1434 & 839 & 738 & 475 & 428 & 399 & 374 \\
\hline Nitr. - removal $70 \mu \mathrm{m}$ & 1590 & 1370 & 1530 & 970 & 407 & 421 & 391 & 386 & 412 \\
\hline
\end{tabular}




\section{Control of heat treatment and chemical heat treatment using the ultrasonic met- hod}

The behavior of the ultrasonic wave passing throug the material is strongly influenced by its elastic, resp. indirectly by plastic properties. The ultrasonic wave is absorbed and scattered. The degree of scattering and absorption can be assessed by quantification and analysis of the ultrasonic wave passed through the material. Since the chemical heat treatment affects the elastic properties of the surface layers of the material to varying degrees, it can be assumed that the chemical heat treatment used will consequently affect the behavior and propagation of the ultrasonic wave.

The measured parameters characterizing the degree of absorption or scattering can include commonly measured wave functions, ie wave propagation speed, amplitude change, RMS value, frequency, wave delay, nominal attenuation, rise time, etc. These parameters can be evaluated directly using an ultrasonic device, or using any oscilloscope.

In order to fully characterize the elastic properties of a material, it is necessary to determine its Young's modulus, as well as the shear modulus and Poisson's ratio, which are the physical quantities that most precisely define the whole elastic properties. These quantities can be easily determined from the speed of propagation of longitudinal and transverse waves while knowing the density of the material.

The speed of propagation of longitudinal ultrasonic waves is given by:

$$
C_{L}=\sqrt{\frac{E}{\rho} \cdot \frac{1-v}{(1+v)-(1-2 v)}},
$$

where: $[\mathrm{m} / \mathrm{s}]$

$\mathrm{c}_{\mathrm{L}}$...propagation velocity of longitudinal waves

E...Young's modulus [Pa]

v...Poisson's ratio [-]

Q...density $\left[\mathrm{g} / \mathrm{cm}^{3}\right]$

The speed of propagation of transverse ultrasonic waves is given by:

$$
C_{T}=\sqrt{\frac{G}{\rho}},
$$

where:

$\mathrm{c}_{\mathrm{T}} \ldots$ propagation velocity of shear waves $[\mathrm{m} / \mathrm{s}]$

G...shear modulus of elasticity $[\mathrm{Pa}]$

Q...density $\left[\mathrm{g} / \mathrm{cm}^{3}\right]$

By modifying the equation:

$$
\frac{E}{G}=2 \cdot(1+v)
$$

an equation can be obtained for the calculation of the tensile modulus of elasticity depending on the propagation speed of longitudinal and transverse waves:

$$
E=\rho \cdot C_{L}^{2} \frac{(1+\vartheta) \cdot(1-2 \vartheta)}{(1-\vartheta)}
$$

Ultrasonic velocity measurements were performed with an Olympus Epoch 1000i - universal flaw detector using a longitudinal wave probe (operating frequency $10 \mathrm{MHz}$ ) and a transverse wave probe (operating frequency $5 \mathrm{MHz}$ ). In all cases, the Pulse - Echo method was used.

Tables 1-3 show the measured hardness HV0,1 values for individual types of heat treatment samples.

In the case of the carburizing and nitriding process (Tables 4,5,6) a significant effect of the thickness of the nitrided or case-hardened layer on the speed of propagation of ultrasonic waves is evident. With increasing thickness of these layers, there are changes in the speed of propagation of ultrasonic waves, so that with increasing thickness, the value of the Poisson's ratio and consequently also the modulus of elasticity in tension is increased. In the case of the nitrided layer, the effect on the speed of the ultrasonic wave was most noticeable.

In the case of quenched samples, see Table 2, the effect of the hardening foil on the process of quenching of the material was observed, which was also re-

\begin{tabular}{|c|c|c|c|c|}
\hline $\begin{array}{l}\text { Type of chemical } \\
\text { heat treatment }\end{array}$ & Wave type & $\begin{array}{l}\text { Ultrasonic wave } \\
\text { speed }[\mathrm{m} / \mathrm{s}]\end{array}$ & Poisson's ratio [-] & $\begin{array}{l}\text { Young's modulus E } \\
\text { [GPa] }\end{array}$ \\
\hline \multirow{2}{*}{ Carburizing $3 \mathrm{hrs}$} & longitunidal & 6000.00 & \multirow{2}{*}{0.28} & \multirow{2}{*}{282.60} \\
\hline & shear & 3269.75 & & \\
\hline \multirow{2}{*}{ Carburizing 6hrs } & longitunidal & 5900.00 & \multirow{2}{*}{0.33} & \multirow{2}{*}{327.03} \\
\hline & shear & 3232.00 & & \\
\hline \multirow{2}{*}{ Carburizing $12 \mathrm{hrs}$} & longitunidal & 5945.55 & \multirow{2}{*}{0.36} & \multirow{2}{*}{378.06} \\
\hline & shear & 3192.30 & & \\
\hline
\end{tabular}
flected in the ultrasonic properties of the hardened samples.

Tab. 4 Steel 16MnCr5, measured and calculated values for carburizing process. 
Tab. 5 Steel $16 \mathrm{MnCr} 5$, measured and calculated values for quenching process after carburizing.

\begin{tabular}{|c|c|c|c|c|}
\hline $\begin{array}{l}\text { Type of heat tre- } \\
\text { atment }\end{array}$ & Wave type & $\begin{array}{l}\text { Ultrasonic wave } \\
\text { speed }[\mathrm{m} / \mathrm{s}]\end{array}$ & Poisson's ratio [-] & $\begin{array}{l}\text { Young's modulus E } \\
\text { [GPa] }\end{array}$ \\
\hline \multirow{2}{*}{$\begin{array}{l}\text { Quenching without } \\
\text { foil }\end{array}$} & longitunidal & 6370.08 & \multirow{2}{*}{0.20} & \multirow{2}{*}{263.30} \\
\hline & shear & 3543.24 & & \\
\hline \multirow{2}{*}{ Quenching in foil } & longitunidal & 6454.59 & \multirow{2}{*}{0.28} & \multirow{2}{*}{318.53} \\
\hline & shear & 3236.90 & & \\
\hline
\end{tabular}

Tab. 6 Steel 31CrMoV9, measured and calculated values for nitriding process.

\begin{tabular}{|c|c|c|c|c|}
\hline $\begin{array}{l}\text { Type of chemical } \\
\text { heat treatment }\end{array}$ & Wave type & $\begin{array}{l}\text { Ultrasonic wave } \\
\text { speed }[\mathrm{m} / \mathrm{s}]\end{array}$ & Poisson's ratio [-] & $\begin{array}{l}\text { Young's modulus E } \\
\text { [GPa] }\end{array}$ \\
\hline \multirow{2}{*}{$\begin{array}{l}\text { Nitriding - removal } \\
10 \mu \mathrm{m}\end{array}$} & longitunidal & 5903 & \multirow{2}{*}{0.33} & \multirow{2}{*}{327.03} \\
\hline & shear & 3232 & & \\
\hline \multirow{2}{*}{$\begin{array}{l}\text { Nitriding - removal } \\
25 \mu \mathrm{m}\end{array}$} & longitunidal & 6000 & \multirow{2}{*}{0.28} & \multirow{2}{*}{282.60} \\
\hline & shear & 3269 & & \\
\hline \multirow{2}{*}{$\begin{array}{l}\text { Nitriding - removal } \\
50 \mu \mathrm{m}\end{array}$} & longitunidal & 6370 & \multirow{2}{*}{0.20} & \multirow{2}{*}{263.30} \\
\hline & shear & 3543 & & \\
\hline \multirow{2}{*}{$\begin{array}{l}\text { Nitriding - removal } \\
70 \mu \mathrm{m}\end{array}$} & longitunidal & 6453 & \multirow{2}{*}{0.19} & \multirow{2}{*}{258.53} \\
\hline & shear & 3736 & & \\
\hline
\end{tabular}

Another type of measurement consisted in the analysis of the behavior of ultrasonic waves in their interaction with the material. Ultrasonic waves were analyzed using an oscilloscope HDO 4022, which with its technical parameters allows to evaluate the exact course of the ultrasonic wave in its entire spectrum. In this type of measurement, the most important wave parameters were evaluated, for which it can be assumed that they will be affected by the material structure. This type of measurement was performed in the pass-through method, ie the ultrasonic wave was generated by an ultrasonic flaw detector on one side of the sample, at the opposite end of the sample was placed an ultrasonic probe that received the signal. The experiment showed that the most significant changes due to heat treatment and chemical heat treatment material occur in the parameters RMS, mean wave amplitude, maximum wave amplitude, wave delay, and frequency. A schematic example of ultrasonic wave analysis by oscilloscope HDO 4022 is shown in Fig.1.

The differences of these measured values of selected wave parameters between carburized, nitrided and quenched samples are shown in graphs $1-3$. For casehardened layers a significant dependence on the layer thickness was found only for the RMS parameter. The other parameters did not show any dependence. On the other hand, in the case of nitrided layers, a strong dependence of the influence of wave functions on chemica heat processing was found for all evaluated parameters - see graph 2 . The influence of wave parameters due to different quenching methods was also found in the hardened samples - see graph 3. In contrast to previous types of chemical heat treatment, the measurement of quenched samples shows an effect on the change in the frequency of the ultrasonic wave, which indicates a dominant influence on the transmitted wave due to scattering and wave refraction.

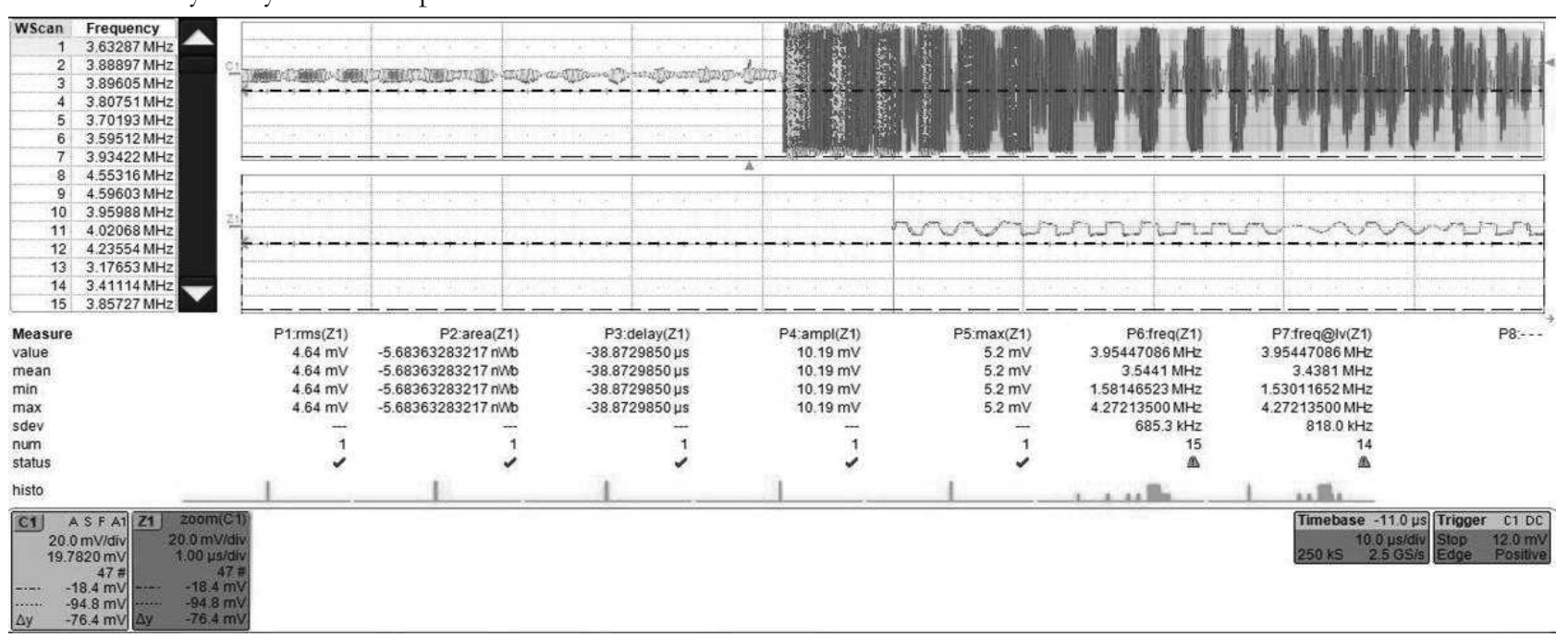

Fig. 1 Ultrasonic wave signal analysis using an oscilloscope, case-hardened sample. 


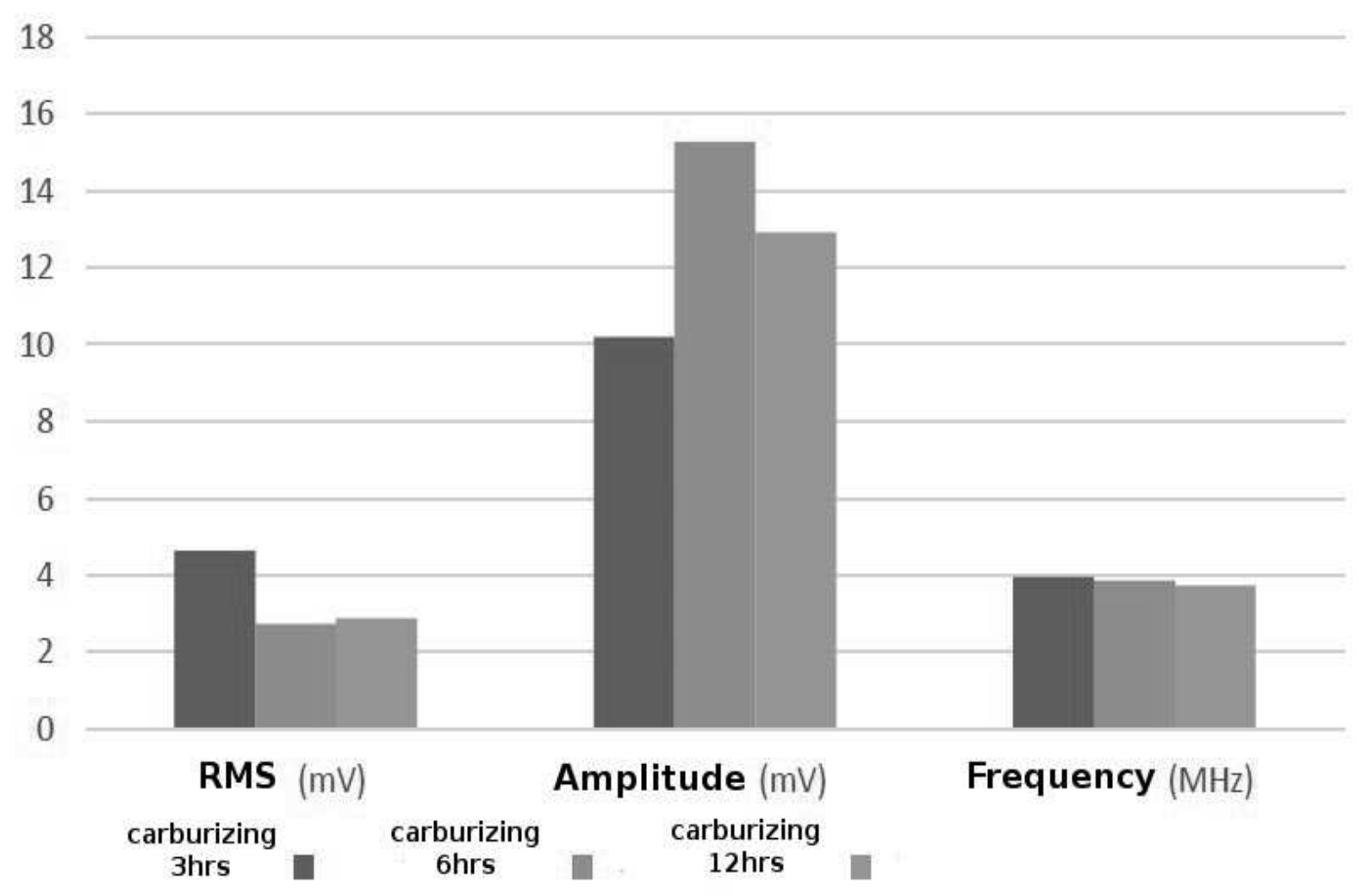

Graph 1 Evaluation of wave characteristics of case-hardened samples.

25

20

15

10

5

0

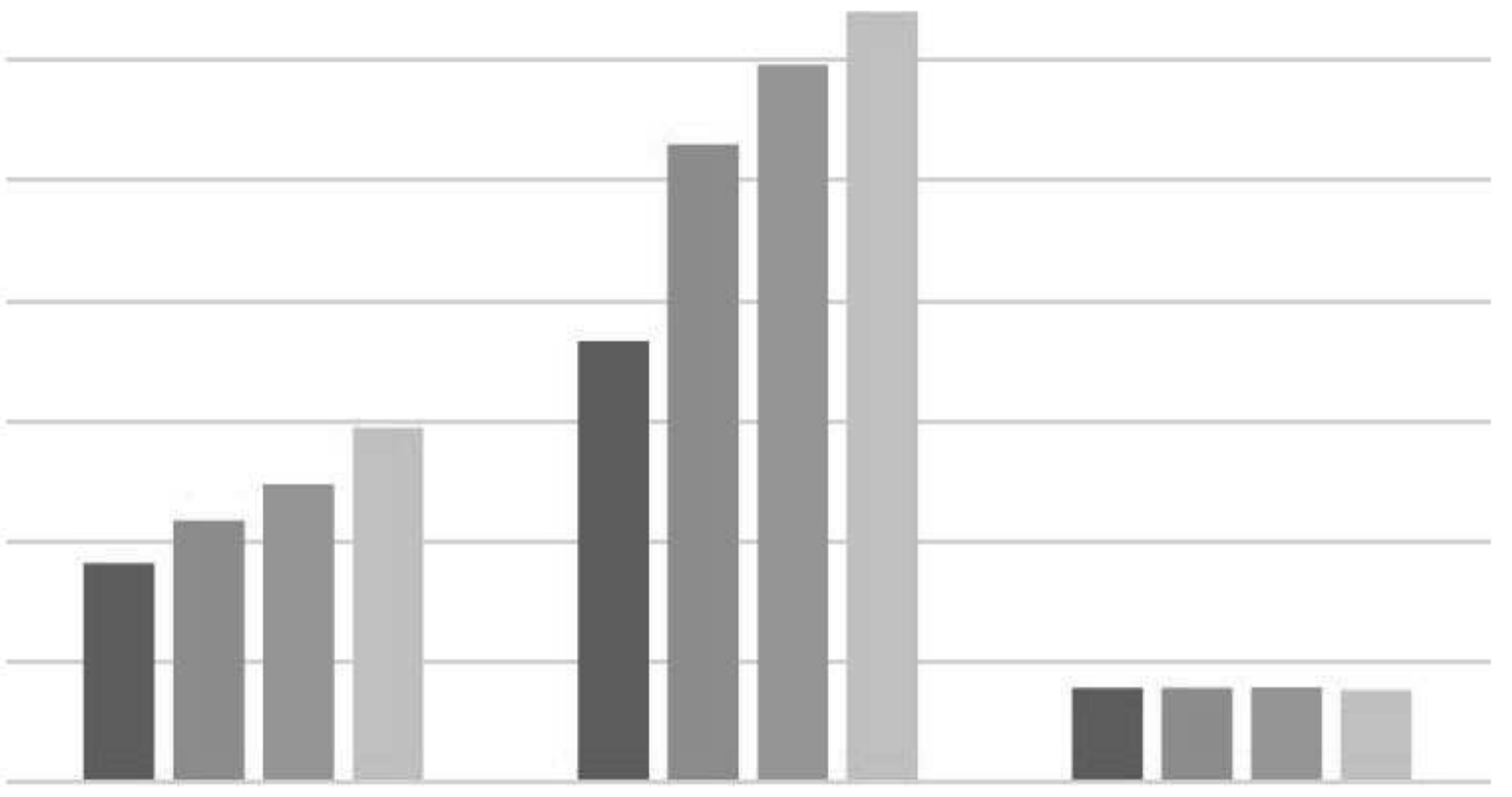

RMS (mV)

Amplitude $(\mathrm{mV})$

Frequency $(\mathrm{MHz})$

nitriding - $10 \mu \mathrm{m}$ removal nitriding - $20 \mu \mathrm{m}$ removal
nitriding $-50 \mu \mathrm{m}$
removal

nitriding - $70 \mu \mathrm{m}$

removal

Graph 2 Evaluation of wave characteristics of nitrided samples. 


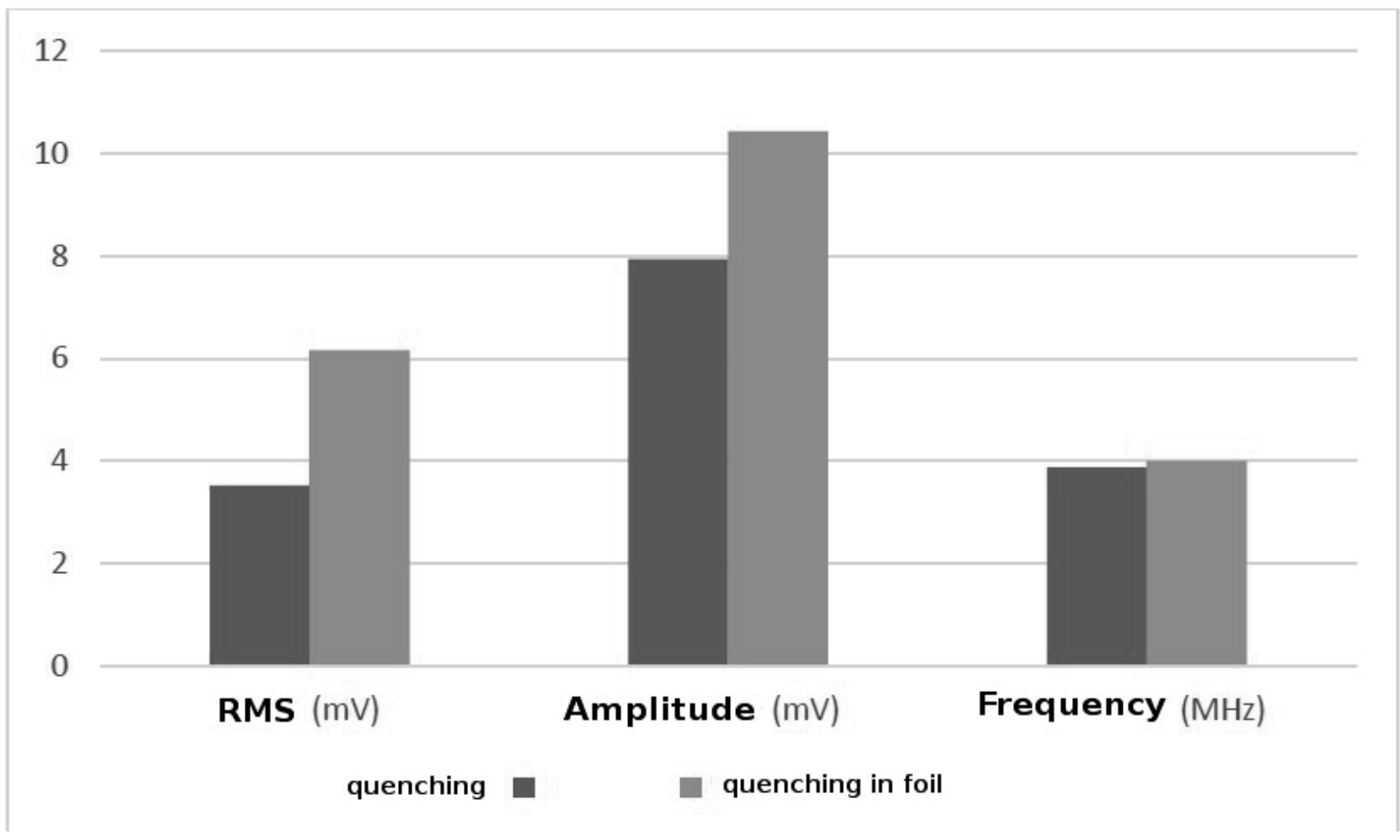

Graph 3 Evaluation of wave characteristics of quenched samples.

\section{Control of heat treatment and chemical} heat treatment by acoustic emission

The principle of verifying the quality of heat treatment and heat treatment is essentially the same as for ultrasonic inspection. The only difference is in the type of acoustic wave used, when the sound event that generated the broadband acoustic wave was used in this measurement. The acoustic signal was excited by the indentation of the hardness measurement method according to the HRC (Rockwell hardness test), or by the impact of the indenter in the case of the dynamic method of the hardness measurement method by the LRHT method (Leeb rebound hardness test).

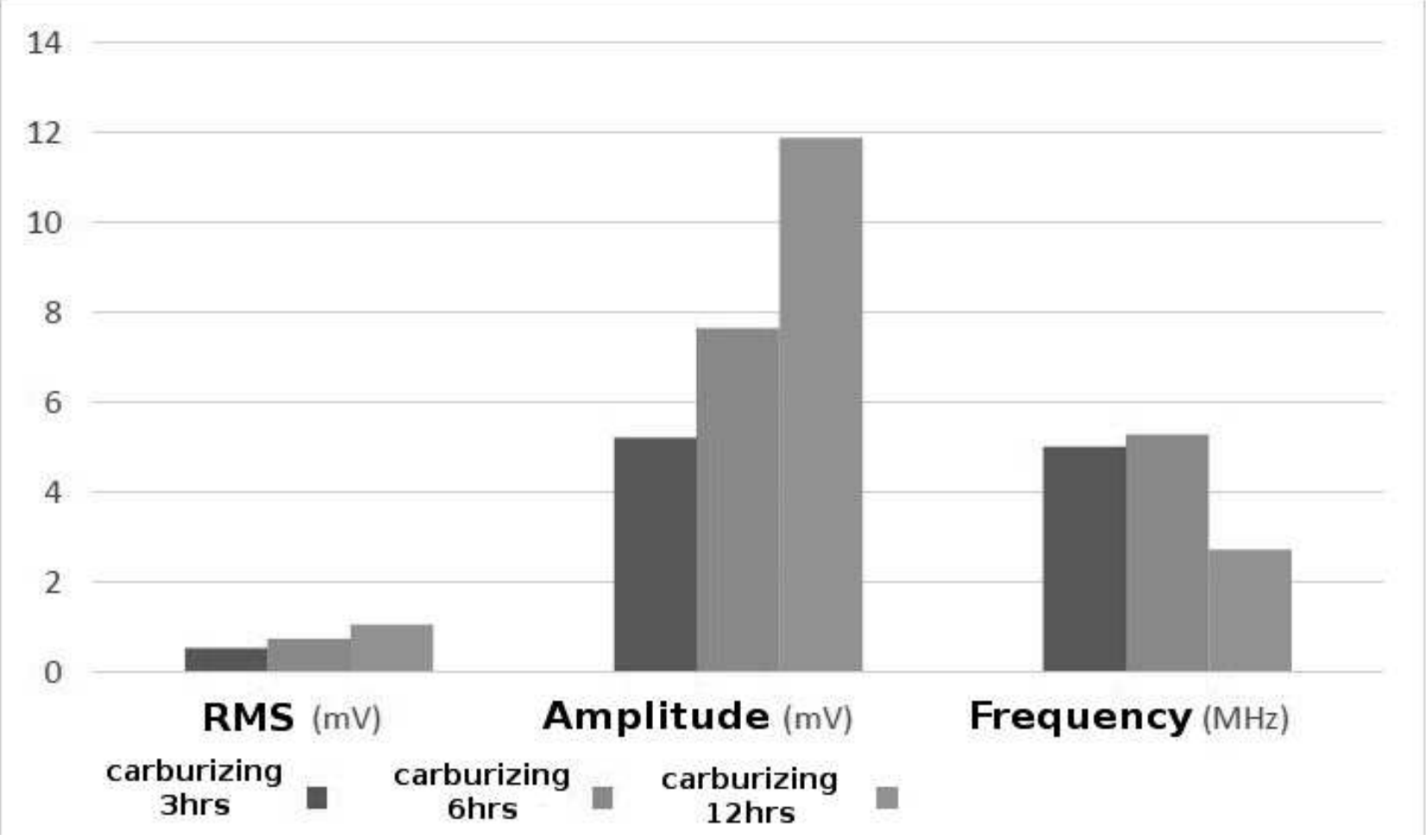

Graph 4 Evaluation of wave characteristics of case-hardened samples when measured by acoustic emission method. 


\section{5}

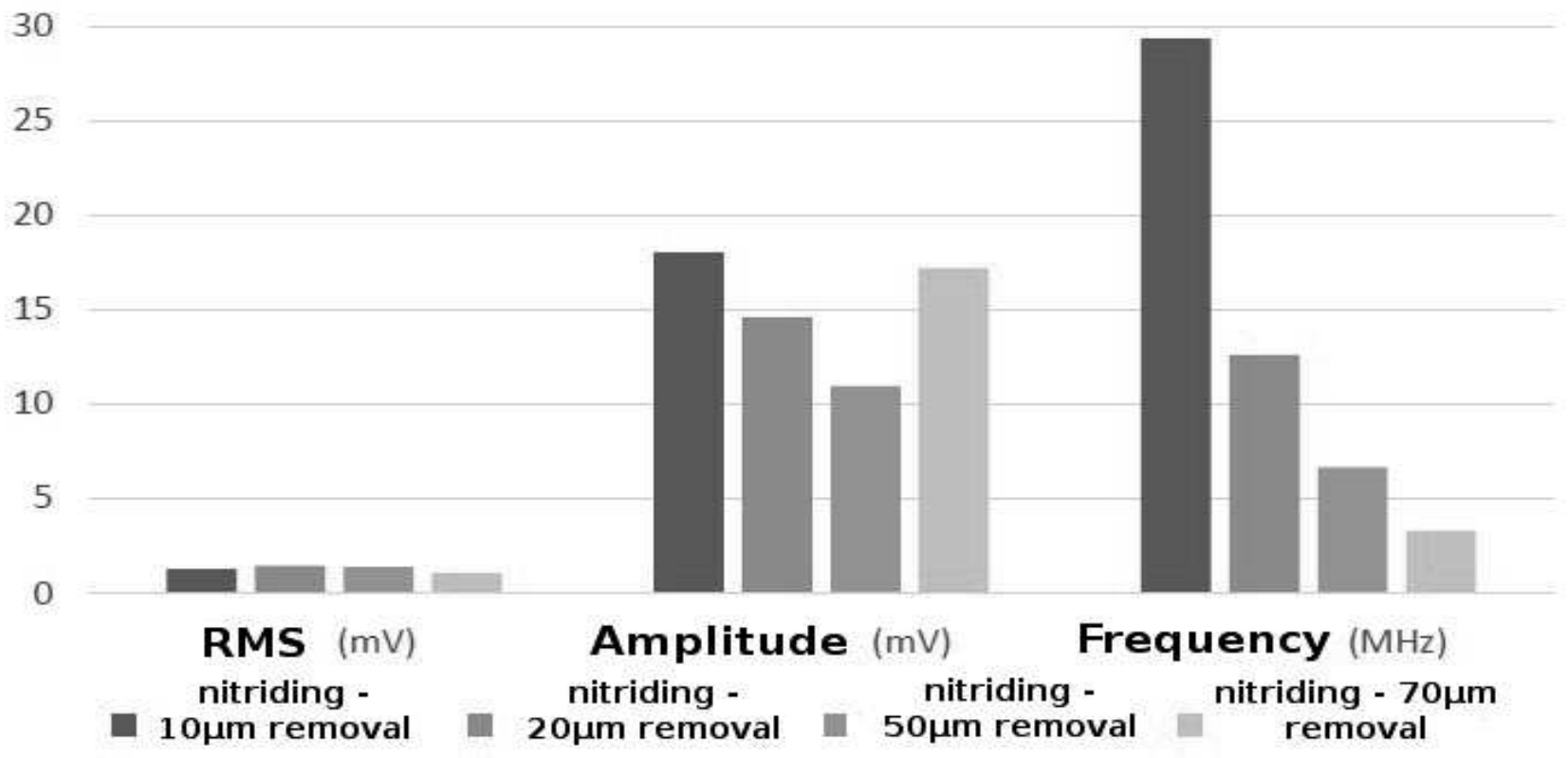

Graph 5 Evaluation of wave characteristics of nitrided samples when measured by acoustic emission method.

Indentation was made on the face of the sample. The acoustic signal was evaluated by a probe placed on the side of the measured sample. A broadband probe for conventional acoustic emission measurement (IDK-09) was used for the measurement. The recording of the course of the wave passing through the material was again evaluated by an oscilloscope HDO 4022. From the point of view of assessing the influence of the progress of the acoustic wave through the material, the same wave parameters were evaluated as in the ultrasonic control.

In case of carburizing samples, the RMS value is significant, where the stress value increases with the carburizing time (Graph 4). Furthermore, with increasing carburizing layer thickness, an increase in amplitude is noticeable. The dependence of the frequency influence on the layer thickness was not found. It follows that the carburizing process significantly affects the passage of the broadband ultrasound wave through the material.

For nitrided samples, a strong dependence of the wave frequency on the thickness of the nitride layer is evident - graph 5. For the values of RMS and wave amplitude it is not possible to determine the dependence of their values on the layer thickness.

It can therefore be stated that the method of acoustic emission evaluation is only suitable for casehardened layers. In general, this method is not very suitable for practical reasons, as it is very difficult to configure the oscilloscope to capture the acoustic signal correctly due to a very short-lasting acoustic event caused by indentation or impact of the indenter on the sample surface.

\section{Control of heat treatment and chemical heat treatment using the eddy current me- thod}

An Olympus Nortec 500D eddy current flaw detector was used for control. For the measurement, it was important to choose the right type of probe and find specific values of frequency and gain parameters so that the difference in the trajectories of the operating point in the impedance plane is as high as possible for each state of the sample. Furthermore, since the operating frequency influences the depth of penetration of the eddy currents into the material, it was important to choose it so as to cover the entire thickness of the carburizing or nitrided layer if possible. But it is also the operating frequency range is determined by the type of probe used. In the case of this measurement, the frequencies ranges $1 \mathrm{KHz}-50 \mathrm{KHz}, 100 \mathrm{~Hz}$ $2 \mathrm{KHz}$ and $300 \mathrm{~Hz}-10 \mathrm{KHz}$ were used.

Fig. 2 shows the individual trajectories of the working point for the individual carburizing states. For samples carburizing for 3 and 6 hours, the curves are partially obscured, but the trajectory corresponding to 12 hours of carburizing is completely different.

When measuring quenched samples (see Fig. 3), it was found that the evaluation of the state of heat treatment can be performed by all tested frequency ranges, ie in all frequency ranges used there is a noticeable difference in trajectories of the operating point, which proves differences in heat treatment. Similar hight resolution in the trajectories of working points was found in nitrided samples. 


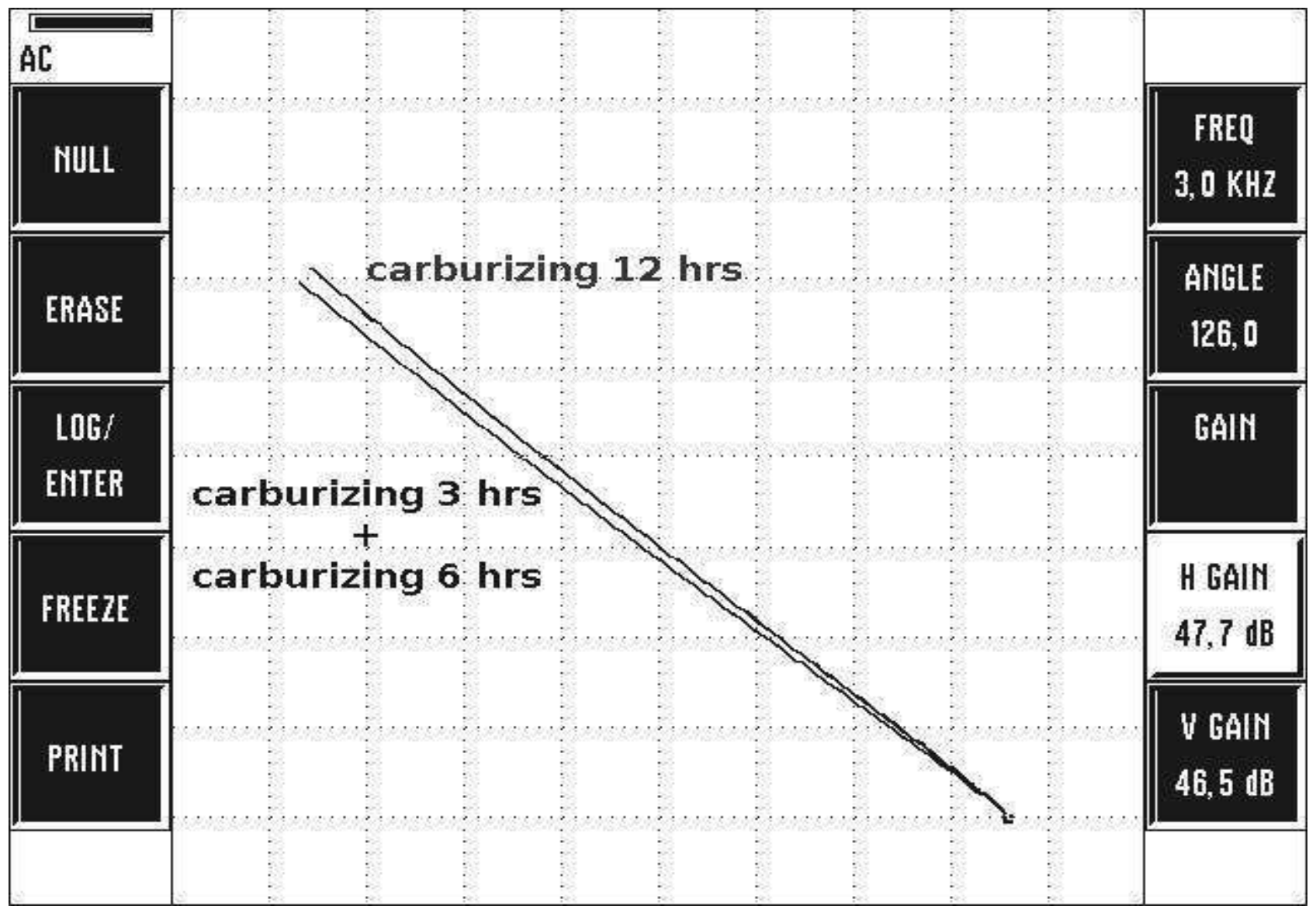

Fig. 2 Trajectories of working points for the case of carburizing samples.

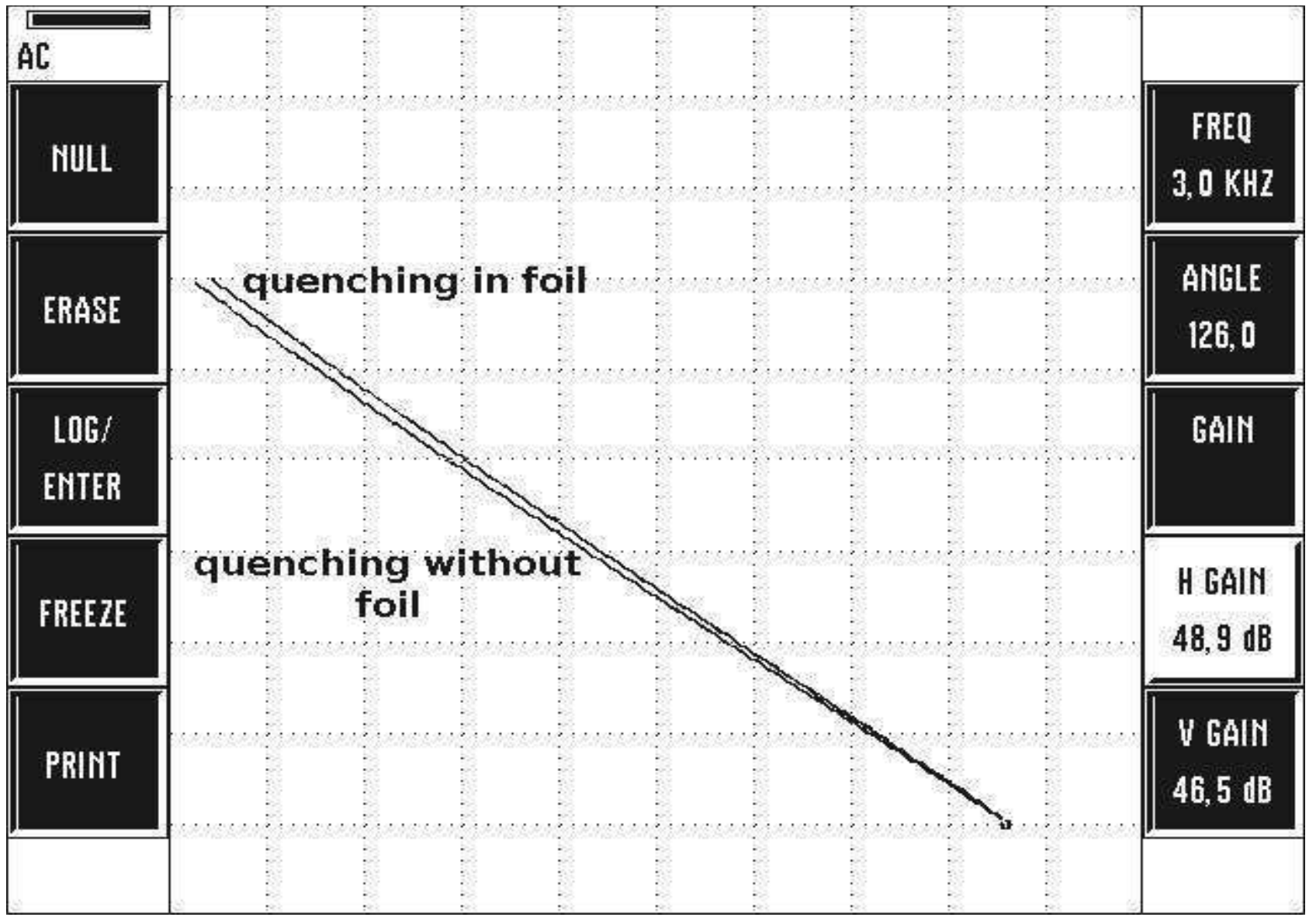

Fig. 3 Trajectories of working points for the case of quenching hardened samples. 


\section{Summary}

Measurements made within this paper, aimed to identify and assess the suitability of conventional NDT techniques for verifying the accuracy and performance of heat treatment and surface hardening. As this is a completely innovative approach and as there is currently no precise procedure for evaluating chemical heat treatment using NDT methods, it was necessary to define appropriate parameters that are clearly influenced by the metallographic structure created during surface hardening or heat treatment.

In case of ultrasonic technique measurements were performed by the due and pulse-echo methods. In case pulse-echo method, the wave signal was subjected to a deeper analysis using an oscillographic record. The generation of the ultrasonic and sound wave took place both by a commonly used piezoelectric probe and by means of an acoustic emission released during the plastic deformation of the surface of the measured material by the indentation or impact of the indenter.

In the oscillographic evaluation, the waves were characterized using suitable wave parameters such as RMS, wave delay, maximum wave amplitude and signal frequency. It was found that the thickness and character of the layer formed by chemical heat treatment as well as the metallographic change of the structure of the material strongly influences these wave quantities. In terms of verification and reproducibility of the results, the ultrasonic method was found to be the most convincing for checking the correctness of chemical heat treatment or chemical heat treatment.

The acoustic emission control was less conclusive and therefore cannot be recommended as a control NDT method. The acoustic emission method is unsuitable for practical reasons due to the complex adjustment procedure and can only be approved for laboratory purposes.
The eddy current method has proven to be also suitable for heat treatment or chemical heat treatment control. A limitation of this method is that the measurement range includes only subsurface and surface areas of the material, whereas the ultrasonic principle is a complete control of the entire volume including the surface.

\section{References}

[1] BENEŠ, P., PRŮCHA, V., HÁJEK, J., VÍTOVEC, V. (2019). Possibility of Using Eddy Current Evaluation of the Heat Treatment of Steel. Manufacturing Technology, 2019, vol. 19, No. 3, 371-374. ISSN: 1213-2489

[2] BENEŠ, P., KOTRBA, M., KŘÍŽ, A. (2016). Alternative uses of eddy current inspection in materials engineering. Manufacturing Technology, 2016, vol. 16, No. 6, 1240-1243. ISSN: 12132489

[3] D. MERCIER, J. LESAGE, X. DECOOPMAN, D. CHICOT (2006). Eddy currents and hardness testing for evaluation of steel decarburizing, NDT \& E International, Volume 39, Issue 8, 2006, 652-660, ISSN 09638695

[4] G.E. TOTTEN, G.E. Totten \& Associates, LLC, M. Narazaki, Utsunomiya University (Japan a R.R. Blackwood and L.M. Jarvis, Tenaxol Inc. Failures Related to Heat Treating Operations.

[5] CANALE, LAURALICE DE CAMPOS FRANCESCHINI, R. A. MESQUITA A GEORGE E. TOTTEN. (2008). Failure analysis of heat treated steel components. Materials Park, Ohio: ASM International, 2008. ISBN 978-087170-868-7. 